\title{
Interaction Between Cibacron Blue F3GA and Luteinizing Hormone: A Chromatographic Investigation
}

\author{
Rajesh Chaudhary ${ }^{1}$, Taruna Arora ${ }^{2}$, Nidhi Vashistha ${ }^{2}$, Sakshi Gera ${ }^{1}$ and K. Muralidhar ${ }^{*}, 2$ \\ ${ }^{1}$ Department of Biomedical Sciences, Acharya Narendra Dev College (University of Delhi), Kalkaji, Delhi-19, India. \\ ${ }^{2}$ Hormone Research Laboratory, Department of Zoology, University of Delhi, Delhi-7, India.
}

\begin{abstract}
Luteinizing hormone which was bound to Cibacron Blue F3GA could not be eluted with 10mM NAD. Bound LH could be eluted partially (up to 5\%) with $80 \%$ ethylene glycol and rest with $50 \mathrm{mM}$ phosphate buffer pH 7.5 containing $1 \mathrm{M} \mathrm{NaCl}$. Each of the bound fractions could also be sub-fractionated with differential elution with a gradient of ethylene glycol or $\mathrm{NaCl}$. This indicated that pituitary LH was a mixture of two different sub-populations of LH, one which interacts with CB predominantly via hydrophobic interactions and the other via electrostatic interaction. In the case of subunits of LH that occur in free state in pituitaries, approximately half of the bound subunits interacted with CB column predominantly via hydrophobic interactions whereas the other half interacted via electrostatic force. It is concluded that differences in glycan content, composition and structure could be the cause for differential binding of buLH and its free subunits to the CBA column.
\end{abstract}

Key words: Cibacron blue F3GA, buffalo LH, interaction, hydrophobic, electrostatic, gonadotropin, ethylene glycol, free subunits.

\section{INTRODUCTION}

Thyrotropin family of pituitary hormones consists of three glycoproteins. ${ }^{1-3}$ All of them are heterodimeric and consist of two subunits denoted as $\alpha$ and $\beta^{1-3}$. The alpha subunit is common to all the hormones (FSH, LH and TSH) of a given species. ${ }^{1,2}$ The beta subunits however differ among these hormones and it confers specific biological function to each of these hormones. ${ }^{1,3,4}$ The two subunits apart from being present in the combined heterodimeric form, also occur in uncombined form as free subunits. ${ }^{5-12}$ These free subunits differ from their corresponding combined forms in the structures of the attached oligosaccharides and also in biological activities. ${ }^{6-12}$ The molecular mass of the heterodimeric form, as shown by various techniques is between $35-45 \mathrm{kDa}$ whereas individual subunits exhibit an apparent molecular mass between 17-22 $\mathrm{kDa}(\alpha$ being smaller than $\beta$ subunit $)^{1}$. These hormones show a great degree of microheterogeneity arising out of differential glycosylation pattern among the molecules of same hormone..$^{2-4,13-15}$ The isoforms so generated also differ in biopotency thus enabling the organism to fine tune their physiological functions in spite of being product of the same gene. ${ }^{14,15}$

Purification of these hormones either from natural sources or culture media has always been a challenge due to their low yield. ${ }^{16}$ The reasons for the low yield are low initial abundance in the source material and losses during biochemical purification protocols. However, to overcome this problem protocols having fewer steps of purification have been developed. ${ }^{17-20}$ To reduce the number of steps, pseudo affinity or immunoaffinity chromatographies have also been incorporated. ${ }^{17,20-24}$

In several cases of pseudo affinity chromatography, the interaction of thyrotropin family of hormones with triazine dyes was exploited. $^{18,20,22,23,25}$ Out of several triazine dyes available, cibacron blue F3GA has been used as pseudo affinity ligand by many workers for purification. ${ }^{18} 20,22$ This dye has been used for purification of many proteins, that possess dinucleotide fold. ${ }^{26-30}$ It has been proposed that cibacron blue is a biomimetic dye, the structure of which resembles ADPribose enabling it to interact specifically with the dinucleotide fold in many proteins. Cibacron blue can also interact nonspecifically with proteins at a site other than the nucleotide binding site. Hence the dye can also bind those proteins which are not known to possess a dinucleotide fold. ${ }^{26-31}$

Protein hormones of thyrotropin family are known to interact with cibacron blue and other triazine dyes. ${ }^{18,20,22,23,25 \text {, }}$

${ }^{32}$ These hormones have been purified using triazine dyes for nearly two decades, ${ }^{22,}, 23,32$ however, reports on the investigation of the nature of interactions between these dyes and the hormones are absent in the literature.

We have previously shown that bubaline $\mathrm{LH}(\mathrm{buLH})$ premixed with blue dextran in solution appeared in void volume along with blue dextran. ${ }^{20}$ Assuming that buLH interacts with cibacron linked to the blue dextran, we have performed preliminary chromatographic investigations to elucidate the nature of interaction between cibacron blue and bubaline 
luteinizing hormone. Results indicate that under appropriate conditions of elution, heterodimeric LH can be fractionated into different isoforms. It has also been shown here that the dye exhibits different binding preferences for the two free subunits (alpha and beta) of buLH.

\section{EXPERIMENTAL \\ Materials}

Pituitary glands were procured from a local abattoir. Glands were from animals of mixed age and sex. Antisera to bLH $\alpha$ and $\beta$ were a kind gift from Dr. J.G. Pierce (Formerly of the Department of Biological Chemistry UCLA, USA). Sephacryl S-200 and S300, Blue dextran- 2000 were purchased from Pharmacia Bio-Tec. Ltd. Sweden. Concanavalin A-agarose (Con AAgarose), medium range SDS-PAGE molecular weight markers and goat anti-rabbit IgG-HRP conjugate were purchased from Bangalore-Genei Ltd. India. ELISA plates were purchased from Greiner, Greiner Bioscience, Germany. SDS-PAGE was performed in an Atto make mini gel system obtained from Atto, Japan. Ortho phenylene diamine (O.P.D.), Coomassie brilliant blue G-250 and $\beta$ mercaptoethanol ( $\beta$ M.E.) were obtained from E Merck Ltd Germany and human Chorionic Gonadotropin (hCG), 4-Chloro $\alpha$-napthol and $\alpha$-methyl mannoside were purchased from Sigma Chemical Co. St. Louis USA. All other chemicals used were of analytical grade.

\section{Methods \\ Preparation of Crude LH from Bubaline Pituitaries}

This was done according to the protocol used for the purification of LH from sheep pituitaries. ${ }^{33}$ but with modifications. The entire process was done at $4-5^{\circ} \mathrm{C}$. Briefly, pituitaries were homogenized in $0.15 \mathrm{M}\left(\mathrm{NH}_{4}\right)_{2} \mathrm{SO}_{4}$ and the $\mathrm{pH}$ of the resulting homogenate was set to 4 using $1 \mathrm{~N} \mathrm{HCl}$. The homogenate was stirred for $2.5 \mathrm{hr}$. after which it was centrifuged at $6500 \mathrm{~g}$ for 30 mins. The resultant extract, was labeled as acid supernatant (AS). To perform dye affinity chromatography with AS it was dialyzed against $50 \mathrm{mM}$ phosphate buffer $\mathrm{pH} 7.5$ containing $0.15 \mathrm{M} \mathrm{NaCl}$, the material obtained after dialysis was called "dialyzed acid supernatant" (ASD). To get crude LH, pH of AS was set to $\mathrm{pH} 3$ using $0.5 \mathrm{M} \mathrm{HPO}_{3}$, the solution stirred for 30 mins. and was then centrifuged at $6500 \mathrm{~g}$ for 30 mins. The supernatant so obtained was neutralized (pH 7) with $1 \mathrm{~N} \mathrm{NaOH}$ and solid $\left(\mathrm{NH}_{4}\right)_{2} \mathrm{SO}_{4}$ added to $50 \%$ saturation and kept stirred for $2.5 \mathrm{hrs}$. at the end the phase separation was achieved by centrifugation. The precipitate so obtained was dissolved and dialyzed against distilled water. The dialyzed material was centrifuged at $6500 \mathrm{~g}$ for $20 \mathrm{mins}$. to remove insoluble precipitate formed during the dialysis. The supernatant recovered was lyophilized and stored at $-20^{\circ} \mathrm{C}$ till use. This material was called as "Crude LH" (50\%PS).

\section{Gel Permeation Chromatography}

Crude LH was passed through a calibrated Sephacryl S-200 or S-300 column $(2.42 \times 145 \mathrm{~cm})$ pre-equilibrated with $0.1 \mathrm{M}$ $\mathrm{NH}_{4} \mathrm{HCO}_{3} .80-100 \mathrm{mg}$ of the crude $\mathrm{LH}$ was dissolved in 5-6 mL of the equilibration buffer and was applied on to the gel bed and eluted at the rate of $28-30 \mathrm{~mL} / \mathrm{hr}$. collecting $5.5 \mathrm{~mL}$ fractions per tube. The absorbance of the fractions was measured at $280 \mathrm{~nm}$. Figure 9 indicates 3 protein peaks. Most of the heterodimeric form of LH was found eluted in the second peak (FIII). The pooling of fractions was done after observing the banding pattern in SDS-PAGE of all the fractions.

\section{Column Chromatography on Cibacron blue F3GA Immobilized to the CL-Agarose}

Columns of cibacron blue F3GA (CBA) were packed in 5 to $10 \mathrm{~mL}$ capacity glass syringes and equilibrated extensively (passing more than 20 column volumes of loading buffer) with $50 \mathrm{mM}$ phosphate buffer $\mathrm{pH} 7.3-7.5 \mathrm{containing} 0.15 \mathrm{M} \mathrm{NaCl}$ hereafter referred to as loading buffer (LB). The unbound protein was collected. Elution of the bound proteins was done step wise either by using different concentrations of ethylene glycol (buffer X: 25\%, Buffer Y: $50 \%$ and buffer Z: $80 \%$ ethylene glycol in $50 \mathrm{mM}$ phosphate buffer $\mathrm{pH} 7.3-7.5)$ or by using different concentrations of $\mathrm{NaCl}$ or $\mathrm{KCl}$ ( $\mathrm{Buffer} \mathrm{A}: 0.3 \mathrm{M} \mathrm{Salt}$, Buffer B: 0.5M Salt, Buffer C: 0.7M Salt, Buffer D: 1M salt, in 50mM phosphate buffer pH 7.3-7.5). Fractions of 3ml in case of $10 \mathrm{~mL}$ column and $2 \mathrm{~mL}$ in case of $5 \mathrm{~mL}$ column were collected. Presence of LH in each fraction was determined either by SDS-PAGE followed by western blot or by direct binding ELISA by loading equal volume of protein solution from each tube in deferent wells of ELISA plate. Experiments were performed at room temperature. To determine the presence or absence of nucleotide binding site in buLH the method indicated by Thompson et.al ${ }^{34}$ was followed. In these experiments ASD was loaded on to the column in loading buffer (LB) and the bound LH was eluted first with 10mM NAD in LB followed by buffer D. All the affinity chromatographic experiments were performed minimum of three times and similar results were obtained each time.

\section{ELISA}

Immunoreactivity of the LH containing samples was measured in triplicate using direct binding ELISA. Antigen dilutions were made in 0.1 M ammonium bicarbonate $\mathrm{pH}$ 7.6-7.8 which was also the coating buffer. The concentration of the sample 
protein coated was kept between $1 \mu \mathrm{g}$. to 100 pico gram. Highly purified homologous LH obtained from earlier batches were used to obtain standard immunoreactivity curve Blocking of the nonspecific sites was done using $1 \%$ casein solution in $0.1 \mathrm{M}$ phosphate buffer $\mathrm{pH}$ 7.5. Primary antibody developed against bLH $\beta$ subunit was used at the dilution of 1:50,000.Goat- anti- rabbit IgG-HRP conjugate was diluted to 1:1500. The entire process including incubation of antibodyantigen solution was done at room temperature. Washing of the wells was done using phosphate buffer (50mM $\mathrm{pH} 7.0)$ containing Tween $(0.05 \%)$. O.P.D. $(1 \mathrm{mg} / \mathrm{mL})$ and $\mathrm{H}_{2} \mathrm{O}_{2}$ in $50 \mathrm{mM}$ citrate buffer $\mathrm{pH} 5.5$ solution was used as substrate. Plates were read at $490 \mathrm{~nm}$ in an ELISA reader. Mean O.D. of the triplicates was taken.

\section{SDS-PAGE}

This was performed according to the method given by Laemmli et.al. ${ }^{35}$ Samples were run under non dissociating conditions i.e. with sample buffer and without boiling the samples, or under reducing dissociating conditions where the samples containing 5\% reducing agent $\beta$ mercaptoethanol ( $\beta \mathrm{ME}$ ) were kept in boiling water bath for 5 mins.or under dissociating but non-reducing conditions where the samples were boiled in the presence of sample buffer without incorporating the reducing agent. Gels were stained in $0.5 \%$ Coomassie brilliant blue in $10 \%$ methanol and $5 \%$ acetic acid overnight.

\section{Western Blot}

Electro transfer of the protein bands from the polyacrylamide gel was done according to the method suggested by Towbin et.al. ${ }^{36}$ The transfer was done at a constant current of 75-80 mAmps for 3-4 hrs. at room temperature (25 degrees Celsius). Blocking of nitrocellulose paper was done with $1 \%$ casein in $0.1 \mathrm{M}$ phosphate buffer $\mathrm{pH} 7.5$ for $1 \mathrm{hr}$. After blocking, the blot was washed with $0.05 \mathrm{M}$ PB pH 7.5 and then it was incubated with the primary antiserum (1: 500 diluted in $0.1 \%$ casein solution in $50 \mathrm{mM} \mathrm{PB} \mathrm{pH} \mathrm{7.5)} \mathrm{for} 3 \mathrm{hrs}$. at room temperature. At the end of incubation the blot was washed as mentioned above and was again incubated with secondary antiserum (1:1000 in $0.1 \%$ casein solution in 50mM PB pH 7.5) for $1 \mathrm{hr}$. at room temperature. After the completion of the incubation the gel was washed thrice with $\mathrm{PB}$ and the immunoreactive bands were visualized by adding the substrate solution $\left(0.03 \% \alpha\right.$-chloro napthol, $0.09 \% \mathrm{H}_{2} \mathrm{O}_{2} \quad 8 \%$ methanol).

\section{Estimation of Protein}

This was done according to the method given by Lowry et al. ${ }^{37}$ using bovine serum albumin as a standard protein.

\section{RESULTS}

Cibacron Blue F3GA in known to bind proteins specifically at their nucleotide binding sites. To determine the presence of nucleotide binding site in buLH the method provided by Thompson et.al. ${ }^{34}$ was followed. The pituitary extract 'ASD' was loaded on to the CBA column. Most of the buLH together with other proteins present in the extract found to be retained by the column (data not shown). The bound proteins were eluted first with 10mM NAD in LB followed by elution of the column with Buffer $\mathrm{D}(1 \mathrm{M} \mathrm{NaCl} / \mathrm{KCl}$, in $50 \mathrm{mM}$ phosphate buffer $\mathrm{pH}$ 7.3-7.5). The pooled fraction under each was concentrated and analyzed for the presence of buLH by SDS-PAGE and western blot. It is clear from figure 1 no LH could be detected in the 10mM NAD eluate (Lane 4, Figure 1). However buffer D eluate had most of the LH (Lane 3, Figure 1). These results indicate absence of a nucleotide binding site in buLH.

To assess the type of interaction between buLH and cibacron blue, ASD was loaded on to the CBA column in LB and the elution of bound proteins was done first with buffer $\mathrm{Z}$ ( $80 \%$ ethylene glycol in $50 \mathrm{mM}$ phosphate buffer $\mathrm{pH} 7.3-7.5$ ) followed by buffer $\mathrm{B}(0.5 \mathrm{M} \mathrm{NaCl}$ in $50 \mathrm{mM}$ phosphate buffer $\mathrm{pH} 7.3-7.5)$ and $\mathrm{D}$ stepwise (Figure 2). For immunological measurement highly purified buLH was used to plot standard curve in case of quantitative analysis. Results obtained after immunoreactivity measurement of each eluate indicated that LH could be eluted by all the three buffers (Z, B and D) (Figure 3). However, the amount of LH immunoreactivity present in materials eluted by different buffers was different (Table1). $74.5 \%$ of the total LH immunoreactivity present in the ASD was retained where as $25.42 \%$ remained unbound. Of the total immunoreactivity applied on the column, 3.78\%, 31.3\% and 39.5\% immunoreactivity appeared in the material eluted with buffers Z, B and D respectively (Table 1). In others words more than $95 \%$ of the total bound LH immunoreactivity could be eluted with salt solutions (buffers B and D) whereas remaining 5\% was eluted by buffer Z ( $80 \%$ ethylene glycol). These results indicated that most of the bound $\mathrm{LH}$ interacted with the matrix predominantly by electrostatic interactions and that too with different strengths. SDS-PAGE analysis (done under non dissociating condition) of pooled fractions eluted under different buffer conditions is shown in figure 4. It can be seen that the salt eluted fraction (fraction eluted with buffer D and B were mixed and concentrated) contained a prominent band (Lane SA) immediately above the $29 \mathrm{kDa}$ region in the gel which is the position of native dimeric LH.

Gonadotropins generally exist in two size forms in tissues i.e. native heterodimeric (a dimer of $\alpha$ and $\beta$ subunits), monomeric free subunits (uncombined $\alpha$ and $\beta$ subunits). A third less well defined form has also been observed which are 
formed by aggregation of free subunits. ${ }^{38-41}$ Under non dissociating conditions in SDS-PAGE the free subunits appear as two close but distinct bands near $20 \mathrm{kDa}$, the heterodimeric form appears near $29 \mathrm{kDa}$ and the aggregated forms appears as several thin sharp bands above the $43 \mathrm{kDa}$ region..

To understand which of the three above mentioned forms of LH interacts preferably with cibacron blue, western blot analysis was done. The blots were probed separately with antibodies specific for $\alpha$ subunit and $\beta$ subunit of bovine LH. The result obtained is shown in figure 5. It is evident from figure $5 \mathrm{~A}$ that when probed with $\alpha$ specific antiserum all the three types of bands (corresponding to free subunits, heterodimeric and aggregate forms) were illuminated in eluate with, salt solution (Lane SA) and in unbound (Lane UB) to the cibacron. Similar results were obtained when another blot was probed with $\beta$ subunit specific antiserum (Figure 5B). However the intensity of illumination of the three types of bands by $\beta$ antiserum in ethylene glycol eluted fraction (Lane ET, Figure 5B) was higher as compared to the material eluted by same buffer but probed with $\alpha$ specific antiserum (Lane ET, Figure 5A).To clarify this further pure LH was loaded and differentially eluted. When the immunoreactivity of all the three fractions (unbound, salt eluted and ethylene glycol eluted fraction) was measured against anti $\alpha$ and anti $\beta$ antiserum in ELISA, all the three reacted well (Figure 6) These results indicated that all the three forms of buLH (free subunits, heterodimeric and aggregated forms) can bind to cibacron blue, and that some of the free $\beta$ subunit and its aggregates as well as heterodimeric LH elute preferably with ethylene glycol. Apart from this there is some buLH belonging to all the three types mentioned above which did not interact with the cibacron blue column under the buffer conditions used to load (LB) the pituitary extract on the CBA column (Figure 5 A and B, Lane UB).

To determine whether LH which was eluted with $80 \%$ ethylene glycol (Figure 2) was also composed of different population of molecules ${ }^{\dagger}$ capable of interacting with the matrix by different degrees of strength, ASD was loaded on to the CBA column and the bound proteins were eluted step wise with buffers having 25\% (buffer X), 50\% (buffer Y) and $80 \%$ (buffer Z) ethylene glycol (Figure 7). The column was finally stripped with $1 \mathrm{M} \mathrm{NaCl}$ solution (buffer D). The fractions eluted by different buffers were pooled separately and the LH immunoreactivities of each pool was determined (Figure 8). Immunoreactivity profile showed presence of $\mathrm{LH}$ in all the pooled fractions eluted with buffers $\mathrm{X}, \mathrm{Y}$ and $\mathrm{Z}$. From this observation it is evident that LH eluted with $80 \%$ ethylene glycol actually consisted of different sub-populations of hydrophobic form of LH differing in the strength of interaction with the matrix. In a similar experiment an enriched preparation of heterodimeric LH which was obtained after gelfiltration chromatography (Figure 9) of crude LH (see materials and methods) can be fractionated by CBA column by eluting the column with buffer having different concentrations of salt (buffers A, B, C and D, Figures 10 and 11).

It is known that SDS-PAGE done even under nondissociating condition can dissociate some of the heterodimeric form of LH into its constituent subunits. ${ }^{42-43}$ This observation may complicate the result obtained in the western blot analysis shown in the figure 5 where it can be argued that immunoreactivity observed in the blot near $20 \mathrm{kDa}$ region (corresponding to the free subunit) could be due to the subunits formed by dissociation of heterodimeric LH under the influence of SDS, rather than due to naturally occurring free subunits. To rule out this possibility an enriched preparation of naturally occurring free subunits was obtained from gel filtration chromatography (Figure 9) where the pooled fraction FIV contained most of the naturally occurring free $\alpha$ and $\beta$ subunits. This fraction was analyzed by SDS-PAGE under non dissociating condition and immunoreactivity of bands was checked by western blot analysis (results not shown) which indicated the presence of both the subunits in FIV and also, the intensity of immunoreactive heterodimeric LH corresponding band (near $29 \mathrm{kDa}$ region) was very less as compared to the immunoreactivity at region (near $20 \mathrm{kDa}$ region) corresponding to the free subunits. This confirmed that the FIV predominantly contained free subunits whereas the amount of heterodimeric LH was very less.

The material (FIV) was loaded on to the CBA column in LB, elution of the bound proteins was done first with $2 \mathrm{M}$ $\mathrm{NaCl}$ followed by $60 \%$ ethylene glycol solution (Figure 12). Elution pattern of $\alpha$ and $\beta$ subunits from the column was also monitored by measuring the immunoreactivity of each tube against $\alpha$ and $\beta$ subunit specific antiserum (Figure 13). Immunoreactivity measurement done with antiserum specific for $\alpha$ subunit revealed that, out of total immunoreactivity recovered from the column $36.9 \%$ was present in fractions eluted by $60 \%$ ethylene glycol, $33.9 \%$ in $2 \mathrm{M} \mathrm{NaCl}$ eluted fractions and $29 \%$ remained unbound to the column (Table 2). This result indicates that the pattern of percentage distribution of LH immunoreactivity in different buffers is not same in the two cases i.e. when ASD was loaded and eluted with salt and ethylene glycol (Table 1) and when free subunit preparation was loaded and eluted with similar buffers. The same calculation done in the case where the immunoreactivity was measured by beta subunit specific antiserum indicated presence of $48.7 \%$ immunoreactivity in $60 \%$ ethylene glycol, $36.7 \%$ in $2 \mathrm{M} \mathrm{NaCl}$ eluted fractions whereas $14.4 \%$ beta immunoreactivity could not bind to the column (Table 2). These results also confirmed the above findings in western blot analysis that, as compared to alpha, beta immunoreactivity was high in ethylene glycol eluted fractions (Figure 5A and B).

\footnotetext{
${ }^{\dagger}$ Not to be confused with different size forms mentioned earlier. Different population is meant here to indicate different microheterogeneous forms formed after posttranslational modification within each size form.
} 
The present study also provides an alternate way of enriching LH in one step of purification. As shown in Table 1, material eluted with buffer D from the CBA column represented a highly enriched LH preparation with 16 folds enrichment over starting material ASD with $39 \%$ recovery.

\section{DISCUSSION}

Binding of gonadotropins to triazine dyes is an old observation. ${ }^{22,} 23,25,{ }^{32}$ However studies with regard the dye hormone interaction did not receive attention by workers. It is well known that triazine dyes (cibacron blue F3GA) binds proteins specifically at their dinucleotide fold and nonspecifically at other locations within proteins. ${ }^{26-29}$ We had earlier devised a protocol for the purification of buLH by exploiting its capability to bind with blue dextran. ${ }^{20}$

Speculations about the presence of dinucleotide fold in buLH is shown by the present study to be incorrect since buLH bound to the CBA column could not be competitively displaced by 10mM NAD (Figure 1). This method of determining presence of dinucleotide fold in a protein chromatographically has been recommended by several workers. ${ }^{28,29,34,44}$ This result is in harmony with the results obtained from crystal structure of other gonadotropins hCG and FSH where nucleotide fold has not been observed. ${ }^{45}, 46$ Proteins belonging to thyrotropin family have highly conserved amino acid sequence, indicating over all similarity in their three dimensional structure as well., 45,46

With the aim of determining the nature of interaction, an extract of bubaline pituitary (AS) containing most of the naturally occurring LH (all microheterogeneous forms) was applied on to the CBA column in the loading buffer. The bound proteins were eluted with solvent with reduced polarity (80\% ethylene glycol) and other solvents containing high concentration of chaotropic salts, $0.5 \mathrm{M}$ and $1 \mathrm{M} \mathrm{NaCl}$ (buffer $\mathrm{B}$ and $\mathrm{D}$ respectively) (Figure 2). Immunoreactivity by ELISA and western blot revealed the presence of LH in both the salt as well as ethylene glycol eluted fractions (Figure 3, 5 and Table 1). Incorporation of ethylene glycol in one of the elution buffer is known to elute the proteins interacting to the CBA matrix predominantly by hydrophobic interaction..$^{29,31,47}$

As has been mentioned in the results section gonadotropic hormones exist in three size forms i.e. heterodimeric, free subunit and, several aggregated forms of subunits. ${ }^{39-41,48}$ Size isoforms of LH in each pooled fraction was determined by the presence of immunoreactivity at the corresponding molecular mass region in the western blot. It was observed that there are two different populations of $\mathrm{LH}$ within each of the three size forms. Of these, one population predominantly interacted via hydrophobic and the other, via electrostatic interactions (Figure $5 \mathrm{~A}$ and B). Further, the amount of free beta subunit and its aggregates, interacting with matrix preferably by hydrophobic interactions was high as compared to the same forms of alpha subunit (Lane ET, Figure 5B). This observed difference between the two subunits could be due to hydrophobic nature of beta subunit per se and this hydrophobicity was further enhanced by lack or less degree of glycosylation. ${ }^{40,}{ }^{49}$ Further aggregated beta subunits interacts mostly hydrophobically.

Chemically cibacron blue is a dye having anthraquinone ring attached with phenyl rings which are sulfonated. ${ }^{26-28}$ This type of chemical structure enables the dye to interact with other molecules hydrophobically (via anthraquinone ring), electro statically (via sulfonated aromatic rings) or by a combination of both of these. ${ }^{26}$ Large molecules, for example proteins, however, can interact with the dye simultaneously by a combination of hydrophobic and ionic interactions. In such a cases elution of the proteins from the column will be determined mainly by the relative contribution in binding by each of the two types of interaction, for example, proteins interacting with the dye predominantly via electrostatic interactions will be eluted mainly by salt containing buffers whereas those interacting via hydrophobic interactions will be eluted by the buffer of reduced polarity.

Considering the above explanation it can be interpreted that the majority of molecules of buLH (95\% of the total bound) probably interact via a combination of both the interactions and the contribution of electrostatic force to hold single molecule in the column is more than the hydrophobic interaction.

The complexity in the present study arises by the observation that LH immunoreactivity eluted with highest concentration of ethylene glycol (80\%) used, can be further fractionated into different fractions when eluted with lower concentrations of ethylene glycol stepwise (Figure 7 and 8). Similarly LH immunoreactivity eluted by $1 \mathrm{M} \mathrm{NaCl}$ can be fractionated into different fractions by eluting the column stepwise at lower concentrations of $\mathrm{NaCl}$ (Figures 2, 10 and 11). These observations indicate that LH eluting with highest concentration ethylene glycol (80\%) was composed of different subpopulations of LH molecules interacting with the matrix with different degree of hydrophobicity. In a similar way LH eluting with $1 \mathrm{M} \mathrm{NaCl}$ was composed of different sub-populations of $\mathrm{LH}$ interacting with the matrix with different degree of electrostatic attractions. This behavior of LH on cibacron blue column can be explained by considering that LH exists in different glycoforms, which differ from each other in the degree of glycosylation and type of sugars present in the oligosaccharides..$^{2-4}$ Due to the differential glycosylation, LH molecules are divided into several subpopulations. ${ }^{4,2,51,52}$ hence the nature of interaction between LH and cibacron blue is modulated by the structure of its oligosaccharides. LH eluting at lower salt concentrations may have more of negative charge density per molecule, decreasing the strength of its interaction with the matrix. In a similar way the sub-population of LH eluted at higher salt concentration may have less of negative 
charge density. This explanation is based on our previous observation that buLH can be fractionated into different charge isoforms by cation exchangers ${ }^{19,42}$ and the charge difference in the buLH arises due to the differences in the sulfate content in the oligosaccharides which alters the total negative charge density on the molecule. ${ }^{42,51,52}$ Free subunit enriched fraction loaded and eluted with similar buffers as in the case of ASD showed different pattern of elution (Table 2). Percentage of free subunits binding to matrix predominantly via hydrophobic interaction is higher as compared to heterodimeric and aggregated form LH (compare Tables 1 and 2). In other words a substantial percentage of free subunit form of LH prefers to interact with cibacron hydrophobically. The observed high hydrophobicity of some of free subunit might have been brought about by the observed decrease in glycan content when compared to subunits dissociated from intact $\mathrm{LH} .{ }^{10,11}$

The above explanation based on sulphate content can be applied to all the three size forms of LH (heterodimeric, uncombined and aggregated subunits) which elute from the column at different salt concentrations (Figures 2, 10 and 11). Binding of LH to cibacron blue and its fractionation into different hydrophobic forms hence can be explained by considering that, hydrophobicity in LH is generated either due to under glycosylation or due to LH having different molecular structure than usual. The unusual structures may also have arisen due to denaturation during purification or misfolding during its synthesis. ${ }^{39,48}$

Free subunit enriched fraction loaded and eluted with similar buffers as in the case of ASD showed different pattern of elution (Table 2). Percentage of free subunits binding to matrix predominantly via hydrophobic interaction is higher as compared to heterodimeric and aggregated form LH (compare Tables 1 and 2). In other words a substantial percentage of free subunit form of LH prefers to interact with cibacron hydrophobically. The observed high hydrophobicity of some of free subunit might have been brought about by the observed decrease in glycan content when compared to subunits dissociated from intact $\mathrm{LH}^{10,11}$

Here the present study provides valuable information on the nature of interaction between a gonadotropin and cibacron blue. LH appears to bind interact with the cibacron blue by both hydrophobic and ionic interactions, most of the $\mathrm{LH}$ binding predominantly via electrostatic interactions. Cibacron blue appears to interact with heterodmeric, subunit and aggregated forms of LH in a similar way, the free subunits having a higher tendency to bind with hydrophobic forces. The dye can be used to fractionate LH into different microheterogeneous forms and finally the matrix can be used to purify LH preparation in one step. The observations made in the present studies can be further investigated in depth using sophisticated techniques. Effect of variation of oligosaccharide on the binding of gonadotropins with the dye may provide an alternate way to access the types of sugars present in the molecule.

\section{ACKNOWLEDGEMENTS:}

Financial support to RC and NV from CSIR, TA from DST, KM and NV from DU is highly acknowledged.

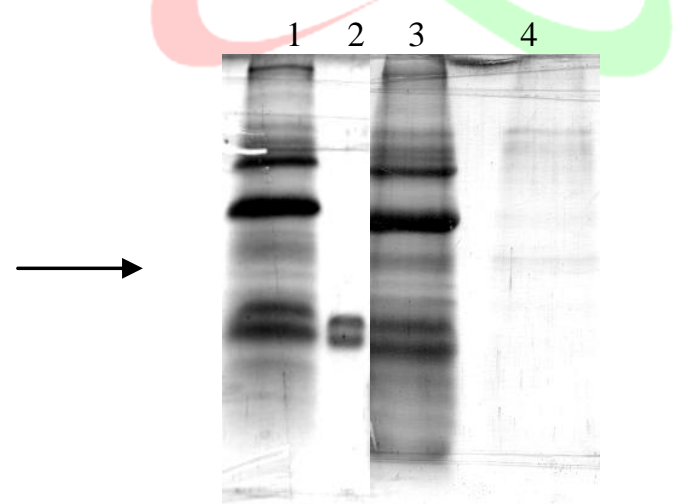

Figure 1: SDS-PAGE (done under reducing dissociating conditions) profile of the bound fractions obtained when ASD was loaded on to the CBA in loading buffer (LB) and eluted step wise with $10 \mathrm{mM}$ NAD and $0.5 \mathrm{M}, 1 \mathrm{M} \mathrm{NaCl}$ containing buffers. Lane 4: bound fractions eluted with NAD, lane 3: eluted with $1 \mathrm{M} \mathrm{KCl}$ after elution of the column with 10mM NAD, lane 2: standard buLH preparation. Lane 1 contained fraction obtained from another chromatography where AS was loaded on to the CBA column and eluted directly with $1 \mathrm{M} \mathrm{KCl}$. Arrow pointing to the bands corresponding to the beta and alpha subunits of LH. 


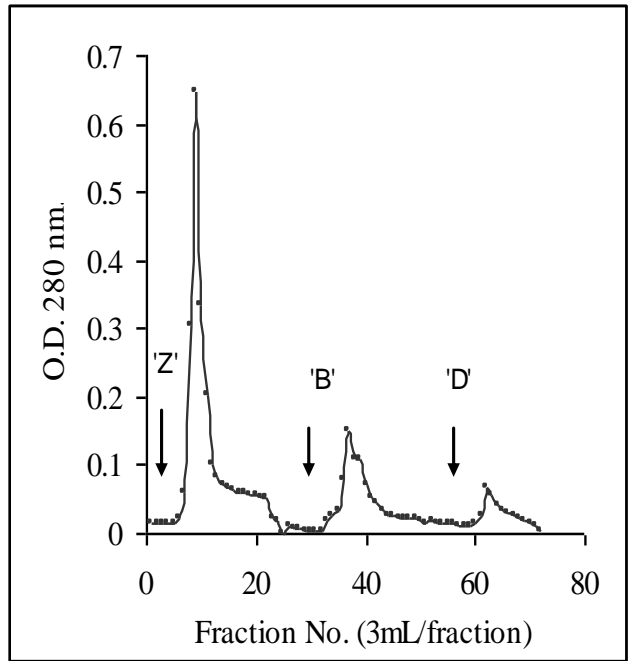

Figure 2: Chromatogram obtained when dialyzed acid supernatant (ASD) was loaded on to the cibacron blue agarose (CBA) column in loading buffer (LB). The bound proteins were eluted with Buffer Z ( $80 \%$ ethylene glycol), buffer B (0.5M Salt) and buffer $\mathrm{D}(1 \mathrm{M}$ salt). Arrows are pointing to the fraction where the buffer was changed to next.

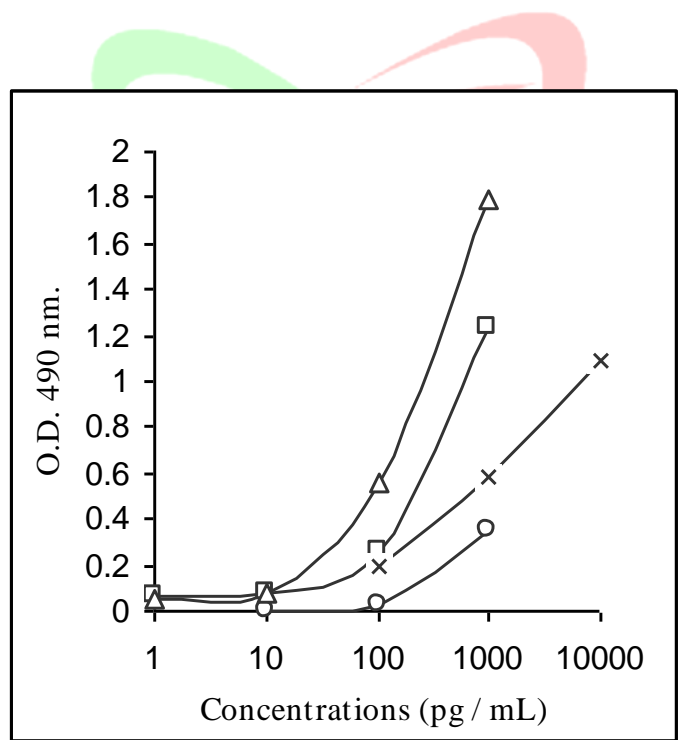

Figure 3: LH immunoreactivity of the pooled fractions corresponding to the Fgure 2. Immunoreactivity of ASD (o), fractions eluted with buffer D $(\Delta)$, buffer B $(\square)$ and Buffer $Z(\times)$. Immunoreactivity measurement was done by direct binding ELISA using anti bLH $\beta$ antiserum as probe. 


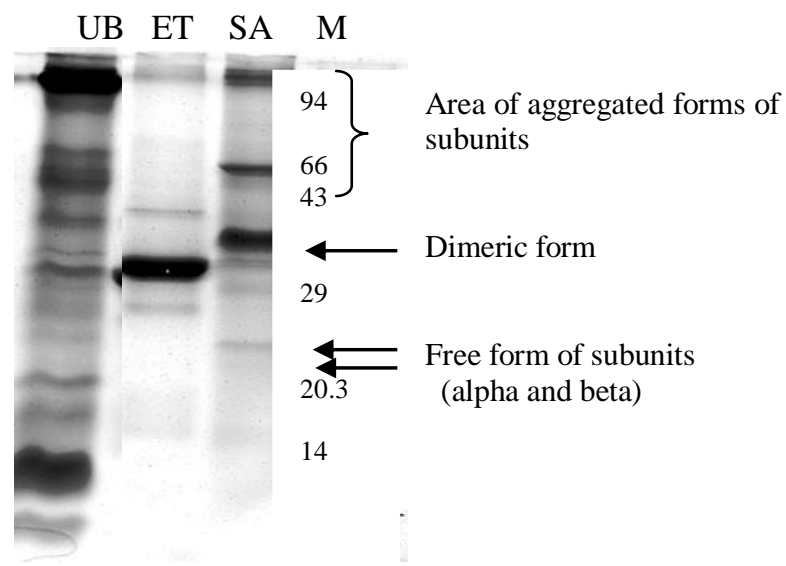

Figure 4: SDS-PAGE analysis (done under non dissociating conditions) of pooled fractions eluted from the CBA column (Figure 2). Lanes UB, ET, SA represent respectively fractions which are unbound, eluted with buffers Z (80\% ethylene glycol) and eluted with buffer $\mathrm{D}(1 \mathrm{M} \mathrm{NaCl}$ in $50 \mathrm{mM}$ phosphate buffer $\mathrm{pH}$ 7.3-7.5). Lane $\mathrm{M}$ contained standard molecular mass markers with their masses indicated. Arrows are pointing to the location of different size forms of LH.

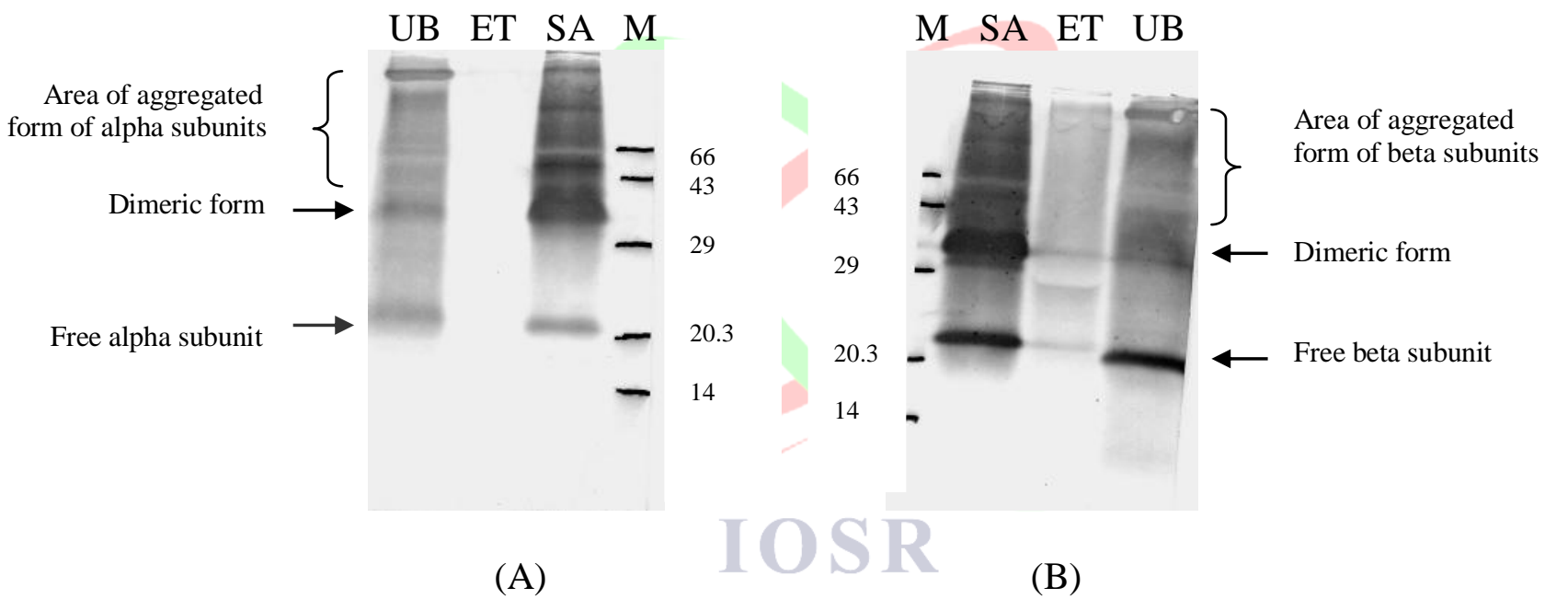

Figure 5: Western blot analysis of the SDS-PAGE shown in the figure 4, probed with antiserum specific to $\alpha$ (A) and $\beta$ (B) subunit of bLH. The nomenclatures of the lanes are same as has been provided in the SDS-PAGE (Figure 4). The position of standard molecular marker was marked manually after blot transfer and visualization of the bands by Ponceau S stain. Arrows indicating the position of heterodimeric, uncombined forms (free subunit) of LH whereas several close thin bands above $43 \mathrm{kDa}$ represents aggregated forms of subunits (see text). 


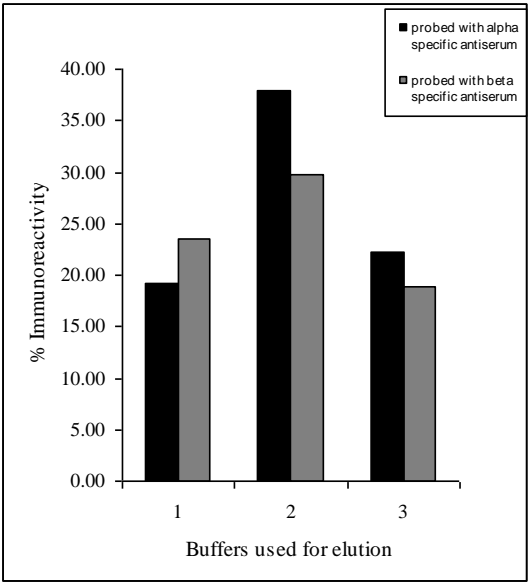

Figure 6: Results obtained when pure LH was loaded on to the CBA column in LB and eluted with buffer D and Z. 1, 2, 3 represents immunoreactivity of fractions which are UB or eluted with buffer $\mathrm{D}$ and $\mathrm{Z}$ respectively, probed with alpha and beta specific antiserum.

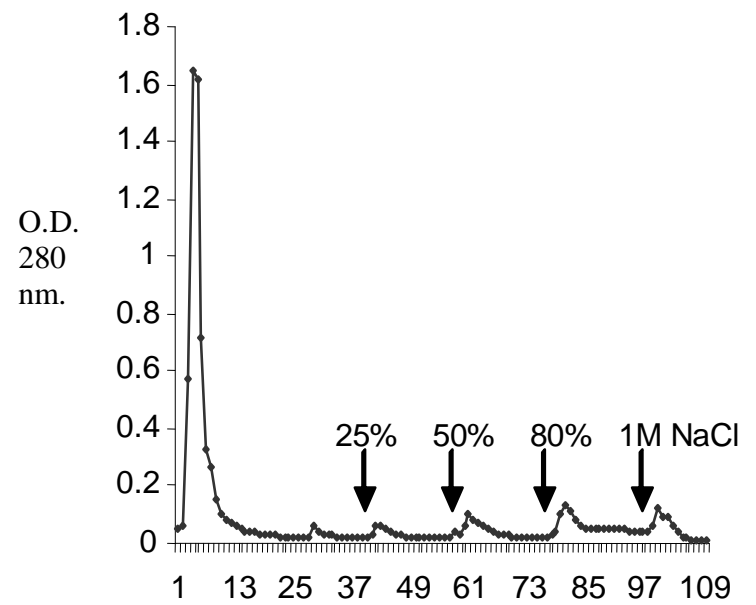

Fraction no. (3 mL/ fraction)

Figure 7: Chromatogram obtained when ASD was loaded on to the CBA column in LB. The proteins retained by the column were eluted with buffers X, Y and Z (see material and methods section). Arrows pointing to the fraction where the buffer was changed to

the next. 


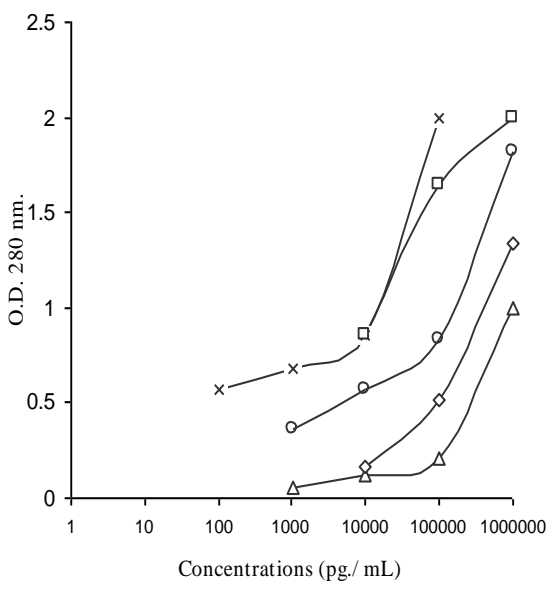

Figure 8: Immunoreactivity profile of the fraction obtained from the chromatography shown in figure 7. $(\diamond)$ eluted with buffer $\mathrm{X},(\circ)$ buffer $\mathrm{Y},(\Delta)$ buffer $\mathrm{Z},(\square)$ fraction eluted finally with $1 \mathrm{M} \mathrm{KCl}$ and $(\times)$ Standard buLH. Immunoreactivity measurement was done in direct binding ELISA using bLH $\beta$ antiserum as probe.

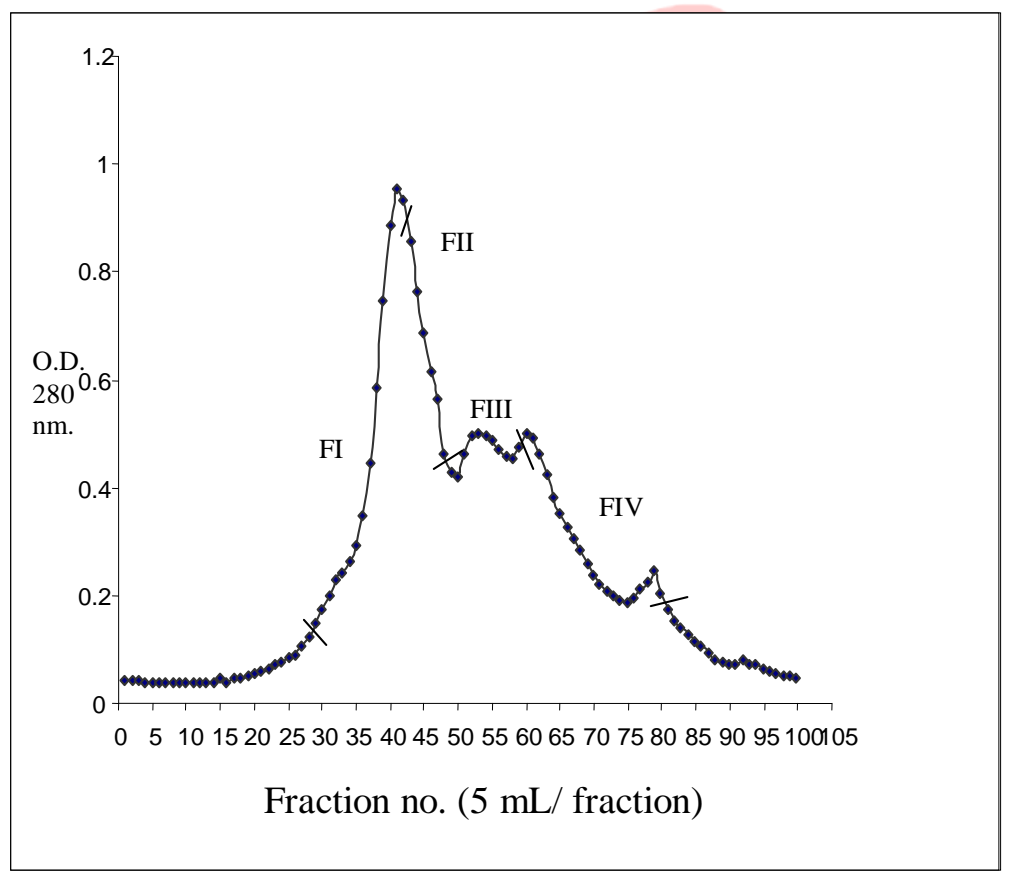

Figure 9: Gel filtration (S-200) chromatography of crude LH (50\%PS). FI, FII, FIII, FIV represents common pools of fractions. Fractions making pool FIII contained most of the native heterodimeric LH whereas most of the free subunits $(\alpha$ and $\beta$ ) of LH eluted in pool FIV. 


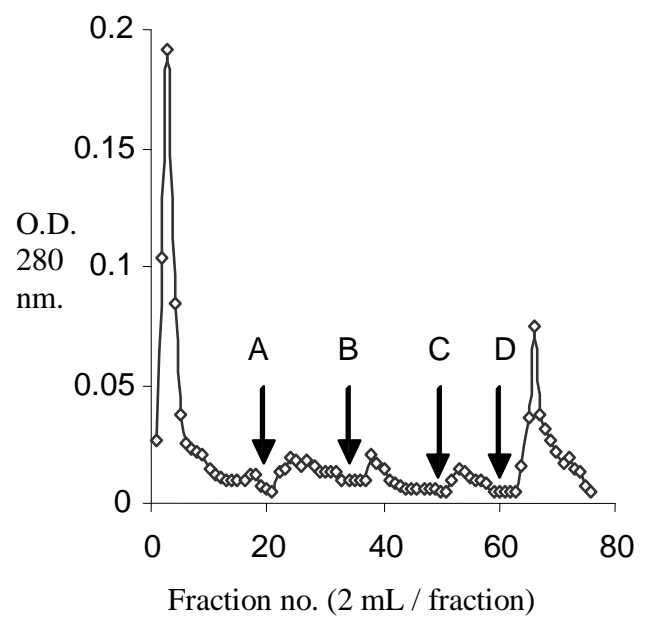

Figure 10: Chromatogram obtained when material obtained from FIII in chromatogram shown in figure 9 (contained most of the heterodimeric form of buLH) was loaded on to the CBA column in loading buffer (LB) and elution of the bound protein was done with buffers A, B, C and D respectively (see material and methods section). Arrows are pointing to the fraction where the buffer was changed.

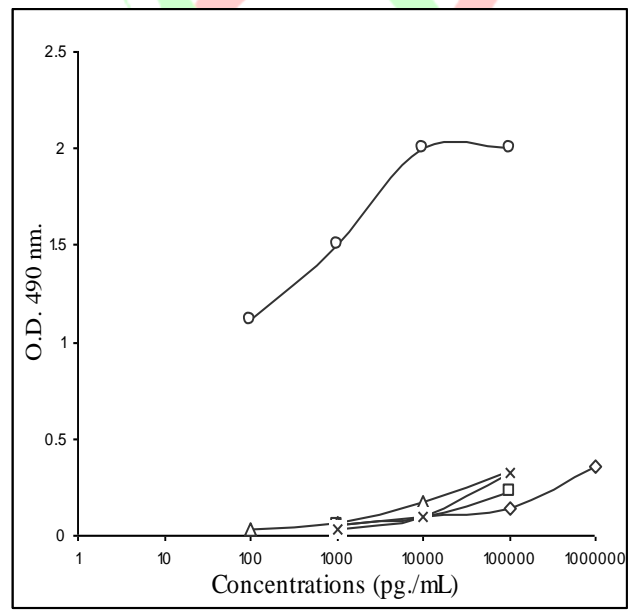

Figure 11: Immunoreactivity of the fraction obtained in the chromatogram shown in figure 10. $(\diamond)$ unbound in LB, ( $\square$ ) eluted with buffer $\mathrm{A},(\times)$ buffer $\mathrm{B},(\Delta)$ buffer $\mathrm{C}$ and $(\circ)$ buffer $\mathrm{D}$. Immunoreactivity measurement was done in direct binding ELISA using anti bLH $\beta$ antiserum as probe. 


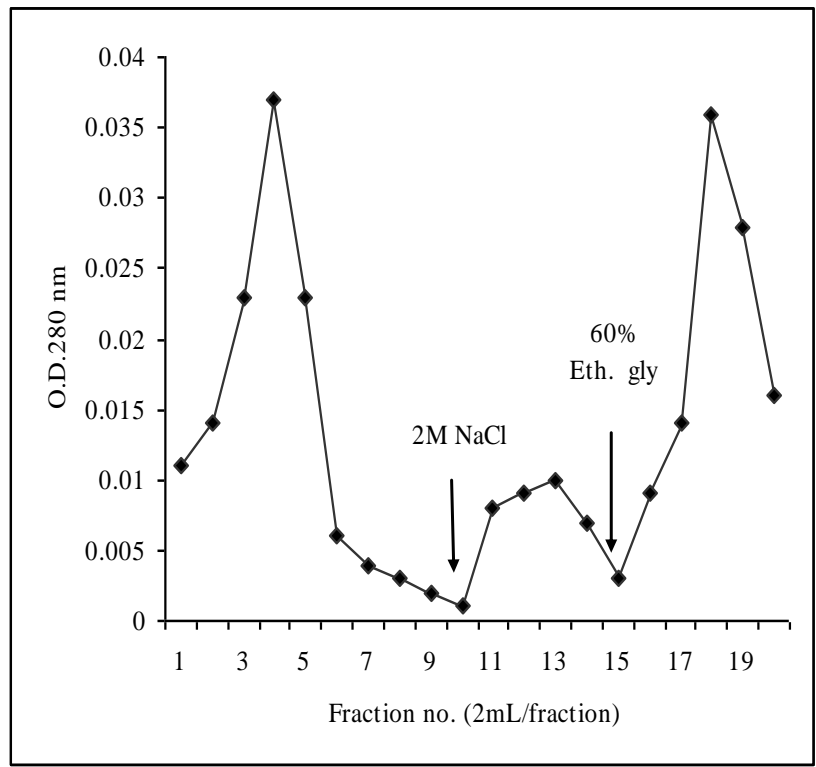

Figure 12: Chromatogram obtained when free alpha and beta subunits containing fraction (FVI) obtained from chromatogram shown in figure 9 was loaded on to the cibacron blue column and eluted with $2 \mathrm{M} \mathrm{NaCl}$ and $60 \%$ ethylene glycol (Eth. gly.). Arrows pointing to the fraction where buffers were changed to next.

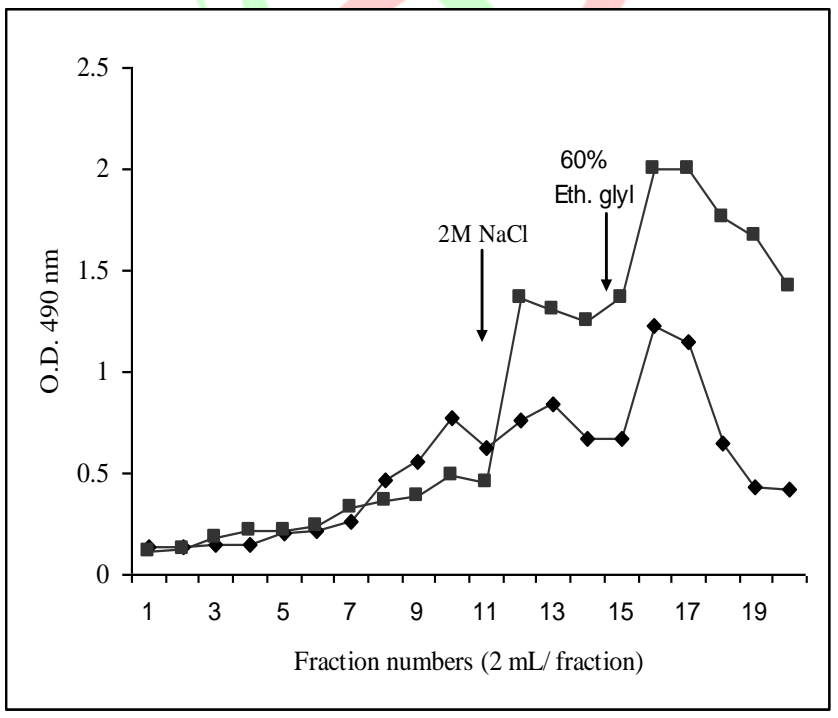

Figure 13: Immunoreactivity profile of each tube obtained when free alpha and beta subunits containing sample was loaded on to the cibacron blue column and eluted with $2 \mathrm{M} \mathrm{NaCl}$ and $60 \%$ ethylene glycol (Eth. gly.). Probed with antibody specific beta subunit ( $\square)$ and alpha subunit $(\diamond)$ of bLH. Arrows pointing to the fractions where buffers were changed to next. 


\begin{tabular}{|c|c|c|c|}
\hline $\begin{array}{c}\text { Percentage of total } \\
\text { LH unbound in } \\
\text { Loading buffer } \\
\text { (LB) }\end{array}$ & $\begin{array}{c}\text { Percentage of total } \\
\text { loaded LH eluted } \\
\text { with 80\% ethylene } \\
\text { glycol (Buffer Z) }\end{array}$ & $\begin{array}{c}\text { Percentage of total } \\
\text { loaded LH eluted } \\
\text { with Buffer B }\end{array}$ & $\begin{array}{c}\text { Percentage of total } \\
\text { loaded LH eluted } \\
\text { with Buffer D }\end{array}$ \\
\hline 25.42 & 3.78 & 31.3 & 39.5 \\
\hline
\end{tabular}

Table 1: Results of estimation of LH in different fractions from CBA column when ASD was loaded as the starting material. Amount of LH was quantified by direct binding ELISA, using highly purified LH as the standard.

\begin{tabular}{|c|c|c|c|}
\hline Antiserum & $\begin{array}{c}\text { Percentage } \\
\text { immunoreactivity in } \\
\text { unbound fraction }\end{array}$ & $\begin{array}{c}\text { Percentage } \\
\text { immunoreactivity in } \\
2 \mathrm{M} \mathrm{NaCl}\end{array}$ & $\begin{array}{c}\text { Percentage } \\
\text { immunoreactivity in } \\
60 \% \text { ethylene glycol }\end{array}$ \\
\hline $\begin{array}{c}\text { Anti LH } \alpha \\
\text { subunit }\end{array}$ & 29.0 & 33.9 & 36.9 \\
\hline $\begin{array}{c}\text { Anti LH } \beta \\
\text { subunit }\end{array}$ & 14.4 & 36.7 & 48.7 \\
\hline
\end{tabular}

Table 2: Distribution of immunoreactivity of free alpha and beta subunits of buLH in different fractions obtained when fraction IV of figure 9 was loaded on to the CBA column.

\section{REFERENCES}

1. Pierce, J.G.; Parsons, T.F. Glycoprotein structure and function. Ann. Rev. Biochem. 1981, 50, $465-495$.

2. Hartree, A.S.; Renwick, A.G.C. Molecular structure of glycoprotein hormone and functions of their carbohydrate components. Biochem. J. 1992, 287, 665-679.

3. Bousfield, G.R.; Li. J.; Ward, D.N. Gonadotropins: Chemistry and biosynthesis; Knobil and Neill's The Physiology of Reproduction, $3^{\text {rd }}$ edition, Neill, J. D. Ed., Elsevier, Academic Press, St. Louis, USA, 2006, 1, 1581-1634.

4. Bousefield, G.R.; Perry, W.M.; Ward, D.N. Gonadotropins: Chemistry and biosynthesis; The Physiology of Reproduction $2^{\text {nd }}$ edition, Knobil, E., and Neill J.D. Eds, Raven Press Ltd., New York, 1994, 1, 1749-1792.

5. Parsons, T.F.; Bloomfield, G.A.; Pierce, J.G. Purification of an alternate form of $\alpha$ subunit of the glycoprotein hormone from bovine pituitaries and identification of its O-linked oligosaccharides. J. Biol. Chem. 1983, 258, 240-244.

6. Blithe, D. L.; Nisula, B.C. Variation in the oligosaccharide on the free and combined $\alpha$ subunit of human chorionic gonadotropin in pregnancy. Endocrinol. 1985, 117, 2218-2228.

7. Blithe, D.L. Carbohydrate composition of the $\alpha$ subunit of human chorionic gonadotropin (hCG $\alpha$ ) and the free $\alpha$ molecules produced in pregnancy: most of free hCG $\alpha$ molecules are fucosylated. Endocrinol. 1990, 126, 2788-2799.

8. Blithe, D.L.; Richards, R.G.; Skarulis, M.C. Free $\alpha$ molecules from pregnancy stimulate secretion of prolactin from human decidual cells: a novel function for free $\alpha$ in pregnancy. Endocrinol. 1991, 129, 22572259.

9. Nemasky, M.; Thotakura, N.R.; Lyons. C.D.; Ye, S.; Reinhold, B.B.; Reinhold, V.N.; Blithe, D.L. Developmental changes in the glycosylation of glycoprotein hormone free $\alpha$ subunit during pregnancy. J. Biol. Chem. 1998, 27, 12068-12076.

10. Arora T.; Muralidhar, K. Microheterogeneity in buffalo thyroid stimulating hormone. J. Endocrinol. Reprod. 1999, 3, 70-80.

11. Arundhati, G.; Das, S.; Muralidhar, K. Isolation and characterization of free subunits of buffalo pituitary luteinizing hormone. J. Endocrinol. Reprod. 2000, 4 35-47. 
12. Chabolt, V.; Magallon, T.; Combarnous, Y. Two free forms of ovine glycoprotein hormone $\alpha$ subunit strongly differ in their ability to stimulate prolactin release from foetal pituitaries. J. Endocrinol. 2000, 164, 287-297.

13. Aguirre, U.A.; Espinoza, R.; Matsumura, P. D.; Larrea, F.; Flores, A.; Morales, L.; Dominguez, R. Studies on the microheterogeneity of the anterior pituitary follicle stimulating hormone in the female rat, isoelectric focusing pattern throughout the estrous cycle. Biol. Reprod.1988. 38, 70-78.

14. Aguirre, A.U.; Midgley, R. Jr.; Beitins, I.Z., Padmanabhan, V. Follicle stimulating isohormones, characterization and physiological relevance. Endocrine. Rev. 1995, 16, 765-787.

15. Aguirre, U.A.; Timossi, C.; de Tomasi, B.; Maldonado, A.; Nayudu, P. Impact of carbohydrate heterogeneity in function of follicle stimulating hormone studies derived from in vitro and in vivo models. Biol. Reprod. 2003, 69, 379-389.

16. Muralidhar, K.; Kumar, R.; Usha, V. Biochemistry and large scale purification of mammalian pituitary gonadotropins. Proc. Natl. Acad. Sci. India. 1998, LXVII, part III and IV, 153-187.

17. Gospodarowicz, D. Single step purification of ovine luteinizing hormone by affinity chromatography. J. Biol. Chem. 1972, 247, 6491-6498.

18. Govoroun, M.S.; Huet, J.C.; Pernollet, J.C.; Breton, B. Use of immobilized metal ion affinity chromatography and dye ligand chromatography for the separation and purification of rainbow trout pituitary gonadotropins. GTHI and GTHII. J Chromatogr B. 1997, 698, 35-46.

19. Chaudhary, R.; and Muralidhar, K. Use of SP-Sephadex to fractionate and obtain semi-pure LH preparation from whole pituitaries of Indian Water Buffaloes (Bubalus bubalis). Prep. Biochem. Biotechnol. 2004, 34, 315-329.

20. Chaudhary, R.; Jain, S.; Muralidhar, K.; Gupta, M. N.; Purification of bubaline luteinizing hormone by gelfiltration chromatography in the presence of blue dextran. Process. Biochem. 2006, 41, 562-566.

21. Hiyama, J.; Surus, A.; Renwick, A.G.C. Purification of human pituitary LH and thyrotropin by hydrophobic chromatography. J. Endocrinol. 1990, 125, 493-500.

22. Wu, J.B.; Stanton, P.G.; Robertson, D. M.; Hearn, M.T.W. Isolation of FSH from bovine pituitary glands J. Endocrinol. 1993, 137, 59-68.

23. Moore, L.G.; Ng-Chie, W.; Lun. S.; Lawrance, S.B.; Young, W.; McNatty, K.P. Follicle stimulating hormone in the Brushtail Possum (Trichosurus vulpecula) purification, characterization and radioimmunoassay. Gen. Comp. Endocrinol. 1997, 106, 30-38.

24. Chiba, K.; Koyabashi, H.; Wakabayashi, K. Isolation and partial characterization of LH, FSH and TSH from canine pituitary glands. Endocrine. J. 1997, 44, 205-218.

25. Bell, L.; Rosenkvich, E.; and Rabinowitz, D. Blue Dextran: Influences on the chromatographic profile and immunoreactivity of human follicle-stimulating hormone (hFSH) (38852), Proc. Soc. Exp. Biol. Med. 1975, 149, 565-569.

26. Scopes, R.K. The use of biospecific elution in purifying proteins from dye-ligand adsorbents; Protein Dye Interactions. Vijayalakshami, M.A. and Bertrand O. Eds, Elsevier Applied Science, New York and London, 1989, 97-106.

27. Dean, P.D.G.; Watson, D.H.; Protein purification using immobilized triazine dyes. J. Chromatogr. 1979, 165, 301-319.

28. Denizili, A.; Piskin, E. Dye ligand affinity system. J. Biochem. Biophys. Methods. 2001, 49, 391-416.

29. Labrou, N.E. Dye-Ligand affinity absorbents for enzyme purification Mol. Biotechnol. 2002, 20, 77- 84 .

30. Swart, A.C.W.; Hemker, H. C. Separation of blood coagulation factors II, VII, IX and X by gel filtration in the presence of dextran blue. Biochim. Biophys. Acta. 1970, 222, 688-692.

31. Jankowski, W.; Muenchhausen, W.; Sulkowski, E.; Carter, W.A. Binding of human interferons to immobilized cibacron blue F3GA: The nature of molecular interactions. Biochem. 1976, 15, 5182-5187.

32. McFarlane, J.R; Czekala, N.M.; Papkoff, H. Zebra chorionic gonadotropin: Partial purification and characterization. Biol. Reprod. 1991, 44, 827-833.

33. Papkoff. H.; Gospodarowicz, D.; Candiotti, A.; Li, C.H. Preparation of ovine interstitial stimulating hormone in high yield. Arch. Biochem. Biophys. 1965, 111, 431-438

34. Thompson, S.T.; Cass, K.H.; Stellwagen, E. Blue dextran-Sepharose: an affinity column for the dinucleotide folds in proteins. Proc. Natl. Acad. Sci. USA. 1975, 72, 669-672.

35. Laemmli, U.K. Cleavage of structural proteins during the assembly of the head of bacteriophase T4. Nature. 1970, 227, 680-685. 
36. Towbin, H.; Staehelin, T.; Gordon, J. Electrophoretic transfer of proteins from polyacrylamide gels to nitrocellulose sheets: procedures and some applications. Proc. Natl. Acad. Sci. USA. 1979, 79, 4350-4354

37. Lowry, O.M.; Rosenbrough, N. J.; Farr, A.J.; Randall, R.J. Protein measurement with the folin phenol reagent, J. Biol. Chem. 1951, 193, 265-275.

38. Huth, J.R.; Norton, S.E.; Lockridge, O.; Shikone, T.; Hsueh, A.J.W.; Ruddon, R.W. Bacterial expression and in vitro folding of $\beta$ subunit of human chorionic gonadotropin (hCG $\beta$ ) and functional assembly of recombinant hCG $\beta$ with hCG $\alpha$. Endocrinol. 1994, 135, 911-918.

39. Ruddon, R.W.; Krzesicki, R.F.; Norton S.E.; Beebe, J.S.; Peters, B.; Perini, F. Detection of a glycosylated, incompletely folded form of chorionic gonadotropin $\beta$ subunit that is a precursor of hormone assembly in trophoblast cells. J. Biol. Chem. 1987, 262, 12533-12540.

40. Corless, C.; Matzuk, M.M.; Ramabhadran, T.V.; Krichevsky, A.; Boime, I. Gonadotropin $\beta$ subunit determine the rate of assembly and the processing of hormone dimer in transfected cells. J. Cell. Biol. 1987, 104, 1173-1181.

41. Furuhashi, M.; Suzuki, S.; Suganuma, N. Disulfide bonds 7-31 and 59-87 of the $\alpha$ subunit play a different role in assembly of human chorionic gonadotropin and lutropin. Endocrinol. 1996, 137, 4196-4200.

42. Sairam, M.R.; Zaky, A.A.; Hassan, A.A. Isolation and characterization of distinct bioactive form of LH from buffalo pituitaries: differences localized to their a subunits. J. Endocrinol. 1994, 143, 313-323.

43. Rajesh Chaudhary thesis work. Submitted to University of Delhi, 2007.

44. Clonis Y.D.; Labrou, N.E.; Kotsira V. Ph.; Mazitsos, S.; Melissis, S.; Gogolas, G. Biomimetic dye as affinity chromatography tools in enzyme purification. J Chromatogr A. 2000, 891, 33-44.

45. Lapthorn, A.J.; Harris, D.C.; Littlejohn, A.; Lustbader, J.W.; Canfield, R.E.; Machin, K.J.; Issac, N.W. Crystal structure of human chorionic gonadotropin. Nature. 1994, 369, 455-461.

46. Fox, K.M.; Dias, J.A.; Roey, P.V. Three dimensional structure of human follicle stimulating hormone. Mol. Endocrinol. 2001, 15, 378-389.

47. Subramanian, S. The use of biospecific elution in purifying proteins from dye-ligand adsorbents; Protein Dye Interactions. Vijayalakshami, M.A. and Bertrand O. Eds, Elsevier Applied Science, London, New York, 1989, 56-71

48. Bedows, E.; Norton, S.E.; Huth, J.R.; Suganuma, N.; Boime, I.; Ruddon, R.W. Misfolded human chorionic gonadotropin $\beta$ subunits are secreted from transfected chinese hamster ovary cells. J. Biol. Chem. 1994, 269, 10574-10580.

49. Krystek, S.R.; Reichert, L.E.; Anderson, TY.T. Analysis of computer-generated hydropathy profile for human glycoprotein and lactogenic hormones. Endocrinol. 1985, 117, 1110-1124.

50. Stanton, P.G.; Robertson, D.M.; Burgon, P.G.; White, B.S.; Hearn, M.T.W. Isolation and physicochemical characterization of human follicle stimulating hormone isoforms. Endocrinol. 1992, 130, 2820-2832.

51. Muralidhar, K.; Kumar, T.R.; Sharma, H.P. Heterogeneity in buffalo lutropin. Ind. J. Biochem. Biophys. 1992, 29, 168-172.

52. Kumar, T.R.; Muralidhar, K. Purification and sulphate content of Buffalo (Bubalus bubalis) pituitary lutropin (LH). Asia. Pacific. Commun. Biochem. 1987, 1, 101-105.

53. Calvo, F.O.; Keutmann, H.T.; Bergert, E.R.; Ryan, R. J. Deglycosylated human follitropin: Characterization and effects on adenosine cyclic 3'5'-phosphate production in porcine granulose cells. Biochem. 1986, 25, 3938-3943. 